\title{
PENERAPAN JOB SHEET BERBASIS ASSESMENT CHECKLIST PRAKTIKUM KERJA BANGKU MATA KULIAH PROSES MANUFAKTUR UNTUK MENINGKATKAN MOTIVASI MAHASISWA TEKNIK INDUSTRI REGULER A ANGKATAN 2018
}

\author{
Agus Widodo \\ Program Studi Teknik Industri/Politeknik META Industri Cikarang \\ agus@politeknikmeta.ac.id
}

\begin{abstract}
During this time students in learning are still experiencing many obstacles, I understand its understanding of image reading, reading of measuring devices and the use of improper hand tools. The subjects of this study were 2018 Regular Industrial Engineering students with a total of 12 students. The results showed that: 1) The process to increase student motivation by using a check sheet job assessment basis sheet can increase student activity in bench work practice. In this case students are required to have their own motivation to be able to do the practice from the results observed from cycle 1 students have increased before doing the practice there are some students who ask the lecturer after the lecturer explains how it works, most students pay attention to the lecturer explain with the application of a job sheet assessment checklist, students are more careful in their bench work practices. 2) The learning method by applying the job sheet assessment checklist can increase the motivation and activeness of students and students more thoroughly in the workpiece work during the learning process of bench work, including: a) motivation, b) responsibility, c) the results of bench work practice. The results of this study indicate that by implementing a job sheet assessment checklist can increase student activity motivation in bench work practice in manufacturing process subjects.
\end{abstract}

Keywords : jobsheet, assessment checklist,manufacturing, student, practice

\begin{abstract}
ABSTRAK
Selama ini mahasiswa dalam belajar masih banyak mengalami kendala, kurang faham nya terhadap pembacaan gambar, pembacaan alat ukur dan penggunaan perkakaks tangan yang kurang benar . Subjek penelitian ini adalah mahasiswa Teknik Industri Reguler A tahun 2018 dengan jumlah mahasiswa 12 orang. Hasil penelitian menunjukan bahwa: 1) Proses untuk meningkatkan motivasi mahasiswa dengan menggunakan job sheet barbasis assesment checklis dapat meningkatkan keaktifan mahasiswa dalam praktek kerja bangku. Dalam hal ini mahasiswa dituntut dapat memiliki motivasi tersendiri untuk bisa mengerjakan praktek tersebut dari hasil yang diamati dari siklus 1 mahasiswa mengalami peningkatan sebelum melakukan praktek ada beberapa mahasiswa yang bertanya kepada dosen setelah dosen menjelaskan cara pengerjaannya, sebagian besar mahasiswa memperhatikan dosen menjelaskan dengan penerapan job sheet assesment checklist, mahasiswa lebih teliti dalam praktek kerja bangku. 2) Metode pembelajaran dengan menerapkan job sheet assesment checklist dapat meningkatkan motivasi dan keaktifan mahasiswa serta mahasiswa lebih teliti dalam pengerjaan benda kerja selama proses pembelajaran praktik kerja bangku berlangsung meliputi: a) motivasi, b) tanggung jawab, c) hasil praktek kerja bangku. Hasil penelitian ini menunjukan bahwa dengan menerapkan job sheet assesment checklist dapat meningkatkan motivasi keaktifan mahasiswa dalam praktek kerja bangku pada mata kuliah proses manufaktur .
\end{abstract}

Kata kunci : jobsheet, assessment checklist, manufaktur, mahasiswa, praktik 


\section{PENDAHULUAN}

Politeknik menyiapkan kebutuhan tenaga kerja tingkat menengah yang punya kemampuan kerja dalam bidang industri sesuai dengan bidangnya masing-masing. Tenaga kerja yang diharapkan memiliki pengetahuan, keterampilan, profesional dan sikap kerja yang sesuai dengan kebutuhan industri. Politeknik ini mempunyai perbedaan dengan sekolah tinggi atau universitas yaitu membekali mahasiswanya dengan keterampilan agar setelah lulus mampu bekerja sebagai operator atau teknisi menengah di industri agar tetap sesuai dengan perkembangan IPTEK dan kebutuhan masyarakat perlu menekankan pada kualitas pendidikan yang didalamnya mengandung adanya unsur-unsur : relevan dengan kegunaan, efesien dalam proses pendidikan, serta peningkatan proses belajar mengajar yang mencakup kertampilan dasar dan keahlian menengah yang dapat dikembangkan sesuai dengan kondisi di dunia kerja .Politeknik tak bisa lagi hanya menyiapkan tenaga kerja siap pakai di dunia usaha dan industri. Para mahasiswa yang telah ditingkatkan kompetensinya sesuai kebutuhan dunia kerja perlu juga dibekali kemampuan berwirausaha agar bisa mandiri. Politeknik adalah salah satu bentuk satuan pendidikan formal yang menyelenggarakan pendidikan pada jenjang pendidikan ahli madya (Diploma III) . Di Politeknik META Industri Cikarang, terdapat banyak mata kuliah praktikum yang sangat relevan dengan dunia industri. Hanya saja saat ini, sistem yang digunakan dalam proses belajar rata rata masih menggunakan metode konvensional atau materi praktikum di dalam kelas, sehingga membuat mahasiswa jenuh dan bosan . Proes pembelajaran praktikum supaya mahasiswa dapat mengusai konsep yang telah diberikan dosen, bagaimana dosen dalam penyampaian materi bisa dimengerti oleh mahasiswa sehingga tidak terjadi salah pengertian, faktor - faktor yang mempengahuri belajar mahasiswa, bagaimana dosen dalam penyampaian materi, media yang digunakan dalam membantu penyampaian materi, faktor yang paling dominan adalah dari mahasiswanya sendiri. Salah satu cara untuk menigkatkan prestasi dan meningkatkan motivasi bagi mahasiswa supaya mahasiswa bisa menguasai materi yang telah diberikan oleh dosen, yaitu mahasiswa diberikan job sheet berbasis assesment check list dengan tujuan mahasiswa lebih teliti dan mampu menilai hasil dari pekerjaannya sendiri. Job sheet berbasis assesment check list adalah terdiri dari job sheet alat untuk membantu mahasiswa memahami langkah-langkah kerja dengan baik. Assessment adalah alih-bahasa dari istilah penilaian. Penilaian digunakan dalam konteks yang lebih sempit daripada evaluasi dan biasanya dilaksanakan secara internal. Penilaian atau assessment adalah kegiatan menentukan nilai suatu objek, seperti baik-buruk, efektif-tidak efektif, berhasil-tidak berhasil, dan semacamnya sesuai dengan kriteria atau tolak ukur yang telah ditetapkan sebelumnya. Check list bentuk penilaian pada diri sendiri dengan menggunakan check list salah satu alat evaluasi yang termasuk alat ukur rating. Dengan penerapan job sheet berbasis assesment check list diharapkan dapat membantu mahasiswa untuk menigkatkan motivasi dalam pembelajaran secara langsung. Mahasiswa belajar didorong dengan kekuatan mentalnya. Kekuatan mental itu berupa keinginan, dorongan, perhatian, dan kemauan yang dapat meningkatkan motivasi. Pengertian motivasi sendiri kekuatan mental yang menjadi penggerak belajar. Kekuatan penggerak tersebut beraasal dari berbagai sumber. Pada peristiwa pertama, motivasi mahasiswa rendah menjadi lebih baik setelah mendapatkan informasi yang benar.

\section{METODE PENELITIAN}

Obyek penelitian ini, mahasiswa yang selama ini kurang semangat dan cepat bosan dalam belajar kembali punya keinginan yang kuat dalam belajarnya. Untuk mengetahui penyebab dari kurang semangatnya mahasiswa dalam belajar. Bagaimanaa agar mahasiswa dalam praktek kerja bangku menjadi lebih semangat dan bergairah dalam belajarnya .Dengan penerapan metode assesment checklist dalam proses pembelajaran praktikum ini diharapkan mahasiwa menjadi semangat, yang selama ini cepat bosan dalam proses pembelajaran. Mahasiswa waktu belajar yang malas, lelah dan kurang dapat memahami materi yang disampaiakan. Metode assesment checklist ini perbaikananya dengan cara wawancara, teknik membaca gambar, membaca alat 
ukur yang benar, penggunaan alat praktikum yang benar dsb. Sehingga mahasiswa bisa menilai sendiri pekerjaan mereka .

\section{HASIL DAN PEMBAHASAN}

Dalam rangka mensiasati kondisi mahasiswa yang malas, kurang mengerti ketika sedang melaksanakan pelaksanaan pembelajaran . Penelitian diharapkan mendapatkan peningkatan sesuai dengan yang diharapkan dengan melakukan penelitian. Untuk mengetahui berhasil dan tidaknya penelitian yang telah dilaksanakan sesuai dengan perencanaan tindakan maka kriteria yang akan digunakan bersumber pada tujuan penelitian yang telah dilakukan. Untuk itu kriteria keberhasilan penelitian data yang dicapai mahasiswa beserta kinerja mahasiswa ini berupa lembar observasi aktifitas belajar mahassiswa selama proses perlakuan. Lembar observasi ini akan diisi oleh observer. Kriteria keberhasilan yang ditetapkan dalam penelitian ini adalah dengan kriteria keberhasilan Baik. Dengan menerapkan job sheet assesment checklist dapat meningkatkan motivasi keaktifan mahasiswa dalam praktek kerja bangku pada mata kuliah proses manufaktur . Dengan metode ini mahasiswa mampu membaca gambar, alat ukur dan penggunaan perkakaks tangan tanpa harus bertanya ulang kepada indtruktur atau dosen .

\section{TABEL DAN GAMBAR}

Bagan model spiral Kemmis dan Mc Taggart digambarkan sebagai berikut:

Ada empat elemen dari penelitian yang dikembangkan yaitu: perencanaan (planing), tindakan (action), pengamatan (observing) dan refleksi (reflecting). Dari empat elemen mempunyai hubungan yang sangat erat seperti yang ada pada gambar berikut;

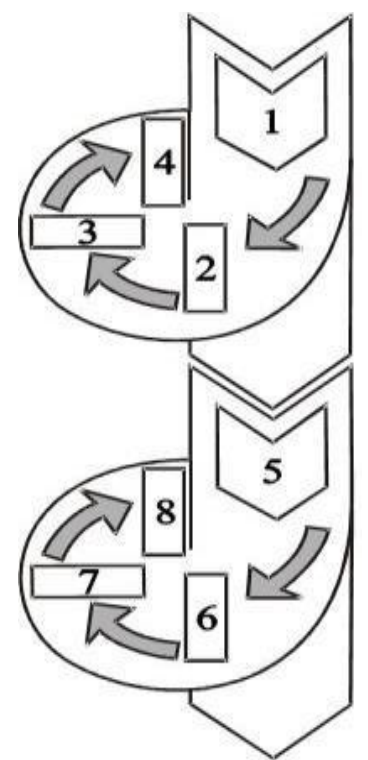

Gambar 1 Elemen penelitian

Keterangan: 1. Perencanaan Pertama 2. Tindakan Pertama

3. Pengamatan Pertama (Observasi ke-1) 4. Refleksi Pertama

5. Revisi terhadap Perencanaan Pertama 6. Tindakan Kedua.

7. Pengamatan Kedua (Observasi ke-2) 8. Refleksi Kedua 
Tabel 2. Kinerja mahasiswa dalam praktek kerja bangku (siklus 1)

\begin{tabular}{|c|l|c|c|}
\hline No & \multicolumn{1}{|c|}{ Uraian } & \multicolumn{2}{|c|}{ observer } \\
\cline { 3 - 5 } & & I & II \\
\hline 1. & Perhatian terhadap materi praktek & $\mathrm{C}+$ & $\mathrm{C}+$ \\
\hline 2. & Mengajukan pertanyaan & $\mathrm{C}$ & $\mathrm{C}$ \\
\hline 3. & Arah Sikap terhadap kegiatan sasaran & $\mathrm{C}$ & $\mathrm{C}$ \\
\hline 4. & Menggunakan alat perkakas sesuai dengan fungsinya & $\mathrm{C}$ & $\mathrm{C}$ \\
\hline 5. & Merapikan dan membersihkan alat setelah praktek & $\mathrm{C}$ & $\mathrm{C}$ \\
\hline 6. & Menjaga peralatan pada waktu praktek & $\mathrm{C}$ & $\mathrm{C}$ \\
\hline 7. & Ketepatan waktu menyelesaikan benda kerja & $\mathrm{C}$ & $\mathrm{C}$ \\
\hline 8. & Hasil praktek kerja & $\mathrm{B}$ & $\mathrm{B}$ \\
\hline
\end{tabular}

Dengan menerapkan metode job sheet assesment checklist mahasiswa dituntut memiliki kemampuan individu diharapkan dalam praktek kerja bangku, dan dapat menyelesaikan praktek kerja bangku tepat pada waktunya. Hasil observasi mahasiswa dalam pelaksanaan pembelajaran dapat dilihat tabel 2.

Tabel 3. Kinerja mahasiswa dalam praktek kerja bangku (siklus 2)

\begin{tabular}{|c|l|c|c|}
\hline No & \multicolumn{2}{|c|}{ Uraian } & \multicolumn{2}{|c|}{ Observer } \\
\cline { 3 - 5 } & & I & II \\
\hline 1. & Perhatian terhadap materi praktek & B & B \\
\hline 2. & Mengajukan pertanyaan & B & B \\
\hline 3. & Arah Sikap terhadap kegiatan sasaran & B & B \\
\hline 4. & Menggunakan alat perkakas sesuai dengan fungsinya & A & A \\
\hline 5. & Merapikan dan membersihkan alat setelah praktek & A & A \\
\hline 6. & Menjaga peralatan pada waktu praktek & A & A \\
\hline 7. & Ketepatan waktu menyelesaikan benda kerja & B & B \\
\hline 8. & Hasil praktek kerja & B & B \\
\hline
\end{tabular}

Dengan metode job sheet assesment checklist mahasiswa dituntut memiliki kemampuan individu sesuai dengan kompetensi yang sesuai diharapkan dalam praktek kerja bangku, dan dapat menyelesaikan praktek kerja bangku tepat pada waktunya. Hasil observasi mahasiswa dalam pelaksanaan pembelajaran dapat dilihat tabel 3. Tabel 3. Kinerja mahasiswa dalam praktek kerja bangku (siklus 2) 
Jurnal Inkofar * Volume 1 No. 1, Juli 2020 * ISSN: 2615-3645 (Print) / 2581-2920 (Online)

Tersedia secara online di: http://www.politeknikmeta.ac.id/meta/ojs/

Tabel 4. Perhitungan kinerja mahasiswa siklus 1 (Observer 1)

\begin{tabular}{|c|c|c|c|c|c|}
\hline \multirow[b]{2}{*}{ No. } & \multirow[b]{2}{*}{ Uraian } & \multicolumn{4}{|c|}{ Jumlah Skor } \\
\hline & & $\mathrm{C}+$ & $\mathbf{B}$ & B+ & $\begin{array}{c}\text { Jumlah } \\
\text { Mahasiswa }\end{array}$ \\
\hline 1 & $\begin{array}{l}\text { Memperhatikan } \\
\text { Instruksi dosen }\end{array}$ & $\begin{array}{c}4 \\
(33.33 \%)\end{array}$ & $\begin{array}{c}5 \\
(41.66 \%)\end{array}$ & $\begin{array}{c}3 \\
(25 \%)\end{array}$ & 12 \\
\hline 2 & $\begin{array}{l}\text { Mengajukan } \\
\text { Pertayaan }\end{array}$ & $\begin{array}{c}4 \\
(33,33 \%) \\
\end{array}$ & $\begin{array}{c}6 \\
(50 \%) \\
\end{array}$ & $\begin{array}{c}2 \\
(16.66 \%) \\
\end{array}$ & 12 \\
\hline 3 & $\begin{array}{l}\text { Arah sikap terhadap } \\
\text { sasaran kegiatan }\end{array}$ & $\begin{array}{c}4 \\
(41.66 \%)\end{array}$ & $\begin{array}{c}5 \\
(41.66 \%)\end{array}$ & $\begin{array}{c}3 \\
(25 \%)\end{array}$ & 12 \\
\hline 4 & $\begin{array}{l}\text { Menggunakan alat perkakas } \\
\text { sesuai fungsinya }\end{array}$ & $\begin{array}{c}3 \\
(25 \%) \\
\end{array}$ & $\begin{array}{c}6 \\
(50 \%) \\
\end{array}$ & $\begin{array}{c}3 \\
(25 \%)\end{array}$ & 12 \\
\hline 5 & $\begin{array}{l}\text { Merapikan dan membersihkan } \\
\text { setelah praktek }\end{array}$ & $\begin{array}{c}3 \\
(25 \%)\end{array}$ & $\begin{array}{c}7 \\
(58.33 \%) \\
\end{array}$ & $\begin{array}{c}2 \\
(16.66 \%)\end{array}$ & 12 \\
\hline 6 & $\begin{array}{l}\text { Menjaga peralatan praktek } \\
\text { kerja dengan baik }\end{array}$ & $\begin{array}{c}2 \\
(25 \%)\end{array}$ & $\begin{array}{c}7 \\
(56.25 \%)\end{array}$ & $\begin{array}{c}3 \\
(18.75 \%)\end{array}$ & 12 \\
\hline 7 & $\begin{array}{l}\text { Ketepatan waktu dalam } \\
\text { pengerjaan benda kerja }\end{array}$ & $\begin{array}{c}3 \\
(25 \%)\end{array}$ & $\begin{array}{c}6 \\
(50 \%)\end{array}$ & $\begin{array}{c}3 \\
(25 \%)\end{array}$ & 12 \\
\hline 8 & $\begin{array}{l}\text { Tidak bercanda pada } \\
\text { waktu praktek kerja }\end{array}$ & $\begin{array}{c}1 \\
(8 \%)\end{array}$ & $\begin{array}{c}9 \\
(75 \%)\end{array}$ & $\begin{array}{c}2 \\
(16.66 \%)\end{array}$ & 12 \\
\hline & Jumlah & $\begin{array}{c}24 \\
(25 \%)\end{array}$ & $\begin{array}{c}53 \\
(55,20 \%)\end{array}$ & $\begin{array}{c}21 \\
(21.875 \%)\end{array}$ & 96 \\
\hline
\end{tabular}

Keterangan : C $=$ Kurang, $\mathrm{C}+=$ Cukup, $\mathrm{B}=$ Baik

Tabel 5. Perhitungan kinerja siswa siklus 1 (Observer 2)

\begin{tabular}{|c|c|c|c|c|c|}
\hline \multirow[t]{2}{*}{ No. } & \multirow[t]{2}{*}{ Uraian } & \multicolumn{4}{|c|}{ Jumlah Skor } \\
\hline & & $\mathrm{C}+$ & $\mathbf{B}$ & $\mathbf{B}+$ & $\begin{array}{c}\text { Jumlah } \\
\text { Mahasiswa }\end{array}$ \\
\hline 1 & $\begin{array}{l}\text { Memperhatikan Instruksi } \\
\text { dosen }\end{array}$ & $\begin{array}{c}2 \\
(25 \%)\end{array}$ & $\begin{array}{c}7 \\
(58.33 \%)\end{array}$ & $\begin{array}{c}3 \\
(16.66 \%)\end{array}$ & 12 \\
\hline 2 & Mengajukan Pertayaan & $\begin{array}{c}3 \\
(41.66 \%)\end{array}$ & $\begin{array}{c}6 \\
(41.66)\end{array}$ & $\begin{array}{c}3 \\
(2.5 \%)\end{array}$ & 12 \\
\hline 3 & $\begin{array}{l}\text { Arah sikap terhadap sasaran } \\
\text { kegiatan }\end{array}$ & $\begin{array}{c}3 \\
(41.66 \%)\end{array}$ & $\begin{array}{c}7 \\
(41.66 \%)\end{array}$ & $\begin{array}{c}2 \\
(18.75 \%)\end{array}$ & 12 \\
\hline 4 & $\begin{array}{l}\text { Menggunakan alat perkakas } \\
\text { sesuai fungsinya }\end{array}$ & $\begin{array}{c}3 \\
(33.33 \%)\end{array}$ & $\begin{array}{c}6 \\
(41.66 \%)\end{array}$ & $\begin{array}{c}3 \\
(25 \%)\end{array}$ & 12 \\
\hline 5 & $\begin{array}{l}\text { Merapikan dan membersihkan } \\
\text { setelah praktek }\end{array}$ & $\begin{array}{c}2 \\
(25 \%)\end{array}$ & $\begin{array}{c}7 \\
(50 \%)\end{array}$ & $\begin{array}{c}3 \\
(25 \%)\end{array}$ & 12 \\
\hline 6 & $\begin{array}{l}\text { Menjaga peralatan praktek } \\
\text { kerja dengan Baik }\end{array}$ & $\begin{array}{c}2 \\
(25 \%)\end{array}$ & $\begin{array}{c}6 \\
(50 \%)\end{array}$ & $\begin{array}{c}4 \\
(25 \%)\end{array}$ & 12 \\
\hline 7 & $\begin{array}{l}\text { Ketepatan waktu dalam } \\
\text { pengerjaan benda kerja }\end{array}$ & $\begin{array}{c}2 \\
(25 \%)\end{array}$ & $\begin{array}{c}7 \\
(50 \%)\end{array}$ & $\begin{array}{c}3 \\
(25 \%)\end{array}$ & 12 \\
\hline 8 & $\begin{array}{l}\text { Tidak bercanda pada waktu } \\
\text { praktek kerja }\end{array}$ & $\begin{array}{c}2 \\
(16.66 \%)\end{array}$ & $\begin{array}{c}7 \\
(58.33 \%)\end{array}$ & $\begin{array}{c}3 \\
(25 \%)\end{array}$ & 12 \\
\hline & Jumlah & $\begin{array}{r}19 \\
(19.79 \%)\end{array}$ & $\begin{array}{c}53 \\
(55.20 \%)\end{array}$ & $\begin{array}{c}24 \\
(25 \%)\end{array}$ & 96 \\
\hline
\end{tabular}

Keterangan : C $=$ Kurang, $\mathrm{C}+=$ Cukup, B $=$ Baik 
Jurnal Inkofar * Volume 1 No. 1, Juli 2020 * ISSN: 2615-3645 (Print) / 2581-2920 (Online)

Tersedia secara online di: http://www.politeknikmeta.ac.id/meta/ojs/

Tabel 6. Perhitungan kinerja mahasiswa pada siklus 2 (Oserver 1)

\begin{tabular}{|c|c|c|c|c|c|}
\hline \multirow[b]{2}{*}{ No. } & \multirow[b]{2}{*}{ Uraian } & \multicolumn{4}{|c|}{ Jumlah Skor } \\
\hline & & $\mathrm{C}+$ & B & B+ & $\begin{array}{c}\text { Jumlah } \\
\text { Mahasiswa }\end{array}$ \\
\hline 1 & Memperhatikan Instruksi dosen & $\begin{array}{c}0 \\
(0 \%) \\
\end{array}$ & $\begin{array}{c}4 \\
(33.33 \%) \\
\end{array}$ & $\begin{array}{c}8 \\
(66.66 \%) \\
\end{array}$ & 12 \\
\hline 2 & Mengajukan pertanyaan & $\begin{array}{c}0 \\
(0 \%) \\
\end{array}$ & $\begin{array}{c}5 \\
(41.66 \%) \\
\end{array}$ & $\begin{array}{c}7 \\
(58.33 \%) \\
\end{array}$ & 12 \\
\hline 3 & Arah sikap terhadap sasaran kegiatan & $\begin{array}{c}0 \\
(0 \%)\end{array}$ & $\begin{array}{c}6 \\
(50 \%)\end{array}$ & $\begin{array}{c}6 \\
(50 \%)\end{array}$ & 12 \\
\hline 4 & $\begin{array}{l}\text { Menggunakan alat perkakas sesuai } \\
\text { fungsinya }\end{array}$ & $\begin{array}{c}0 \\
(0 \%)\end{array}$ & $\begin{array}{c}5 \\
(41.66 \%)\end{array}$ & $\begin{array}{c}7 \\
(58.33 \%)\end{array}$ & 12 \\
\hline 5 & $\begin{array}{l}\text { Merapikan dan membersihkan } \\
\text { setelah praktek }\end{array}$ & $\begin{array}{c}0 \\
(0 \%)\end{array}$ & $\begin{array}{c}5 \\
(41.66 \%)\end{array}$ & $\begin{array}{c}7 \\
(58.33 \%)\end{array}$ & 12 \\
\hline 6 & $\begin{array}{l}\text { Menjaga peralatan praktek kerja } \\
\text { dengan baik }\end{array}$ & $\begin{array}{c}0 \\
(0 \%) \\
\end{array}$ & $\begin{array}{c}5 \\
(41.66 \%) \\
\end{array}$ & $\begin{array}{c}7 \\
(58.33 \%) \\
\end{array}$ & 12 \\
\hline 7 & $\begin{array}{l}\text { Ketepatan waktu dalam pengerjaan } \\
\text { benda kerja }\end{array}$ & $\begin{array}{c}0 \\
(0 \%) \\
\end{array}$ & $\begin{array}{c}5 \\
(41.66 \%) \\
\end{array}$ & $\begin{array}{c}7 \\
(56.25 \%) \\
\end{array}$ & 12 \\
\hline 8 & $\begin{array}{l}\text { Tidak bercanda pada waktu praktek } \\
\text { kerja }\end{array}$ & $\begin{array}{c}0 \\
(0 \%)\end{array}$ & $\begin{array}{c}5 \\
(41.66 \%)\end{array}$ & $\begin{array}{c}7 \\
(56.25 \%)\end{array}$ & 12 \\
\hline & Jumlah & $\begin{array}{c}0 \\
(0 \%)\end{array}$ & $\begin{array}{c}40 \\
(41.66 \%)\end{array}$ & $\begin{array}{c}56 \\
(58.33 \%)\end{array}$ & 96 \\
\hline
\end{tabular}

Keterangan : $\mathrm{C}=$ Kurang, $\mathrm{C}+=$ Cukup, $\mathrm{B}=$ Baik

Tabel 7. Perhitungan kinerja mahasiswa siklus 2 (Observer 2)

\begin{tabular}{|c|c|c|c|c|c|}
\hline \multirow[b]{2}{*}{ No. } & \multirow[b]{2}{*}{ Uraian } & \multicolumn{4}{|c|}{ Jumlah Skor } \\
\hline & & $\mathrm{C}+$ & $\mathbf{B}$ & $\mathbf{B +}$ & $\begin{array}{c}\text { Jumlah } \\
\text { Mahasiswa }\end{array}$ \\
\hline 1 & Memperhatikan Instruksi dosen & $\begin{array}{c}0 \\
(0 \%)\end{array}$ & $\begin{array}{c}3 \\
(25 \%)\end{array}$ & $\begin{array}{c}9 \\
(75 \%)\end{array}$ & 12 \\
\hline 2 & Mengajukan pertayaan & $\begin{array}{c}0 \\
(0 \%)\end{array}$ & $\begin{array}{c}4 \\
(33.33 \%)\end{array}$ & $\begin{array}{c}8 \\
(66.66 \%)\end{array}$ & 12 \\
\hline 3 & $\begin{array}{l}\text { Arah sikap terhadap sasaran } \\
\text { kegiatan }\end{array}$ & $\begin{array}{c}0 \\
(0 \%)\end{array}$ & $\begin{array}{c}6 \\
(50 \%)\end{array}$ & $\begin{array}{c}6 \\
(50 \%)\end{array}$ & 12 \\
\hline 4 & $\begin{array}{l}\text { Menggunakan alat perkakas sesuai } \\
\text { fungsinya }\end{array}$ & $\begin{array}{c}0 \\
(0 \%)\end{array}$ & $\begin{array}{c}4 \\
(33.33 \%)\end{array}$ & $\begin{array}{c}8 \\
(66.66 \%)\end{array}$ & 12 \\
\hline 5 & $\begin{array}{l}\text { Merapikan dan membersihkan } \\
\text { setelah praktek }\end{array}$ & $\begin{array}{c}0 \\
(0 \%)\end{array}$ & $\begin{array}{c}5 \\
(41.66 \%)\end{array}$ & $\begin{array}{c}7 \\
(58.33 \%)\end{array}$ & 12 \\
\hline 6 & $\begin{array}{l}\text { Menjaga peralatan praktek kerja } \\
\text { dengan baik }\end{array}$ & $\begin{array}{c}0 \\
(0 \%)\end{array}$ & $\begin{array}{c}5 \\
(41.66 \%)\end{array}$ & $\begin{array}{c}7 \\
(58.33 \%)\end{array}$ & 12 \\
\hline 7 & $\begin{array}{l}\text { Ketepatan waktu dalam pengerjaan } \\
\text { benda kerja }\end{array}$ & $\begin{array}{c}0 \\
(0 \%)\end{array}$ & $\begin{array}{c}4 \\
(33.33 \%)\end{array}$ & $\begin{array}{c}8 \\
(66.66 \%)\end{array}$ & 12 \\
\hline 8 & $\begin{array}{l}\text { Tidak bercanda pada waktu praktek } \\
\text { kerja }\end{array}$ & $\begin{array}{c}0 \\
(0 \%)\end{array}$ & $\begin{array}{c}4 \\
(33.33 \%)\end{array}$ & $\begin{array}{c}8 \\
(66.66 \%)\end{array}$ & 12 \\
\hline & Jumlah & $\begin{array}{c}0 \\
(0 \%)\end{array}$ & $\begin{array}{c}35 \\
(36.45 \%)\end{array}$ & $\begin{array}{c}61 \\
(63.44 \%)\end{array}$ & 96 \\
\hline
\end{tabular}

Keterangan : $\mathrm{C}=$ Kurang, $\mathrm{C}+=$ Cukup, $\mathrm{B}=$ Baik 


\section{KESIMPULAN DAN SARAN}

1. Metode pembelajaran dengan menerapkan job sheet assesment checklist dapat meningkatkan motivasi dan keaktifan mahasiswa serta mahasiswa lebih teliti dalam pengerjaan benda kerja selama proses pembelajaran praktik kerja bangku

2. Pendekatan pribadi dosen terhadap mahasiswa perlu dilakukan agar mahasiswa memperoleh kepercayaan diri dan merasa ada suasana baru dalam pembelajaran.

\section{DAFTAR PUSTAKA}

Love, G. dan Harun. (1986). Teori dan Kerja Praktek Logam. Jakarta : Erlangga.

Takeshi G. dan N. Sugiarto H. (2005). Menggambar Mesin Menurut Standar ISO. Jakarta: Pradya Paramita

Malik, Ir. Adam, Tim Asisten. 2013. Diktat Praktikum Metrologi Industri. Laboratorium Metrologi Industri. FT-UA : Padang.

Kardun. (1999). Ilmu Proyeksi. Jakarta: Bumi Aksara

Love, G. dan Harun. (1986). Teori dan Kerja Praktek Logam. Jakarta : Erlangga.

Terheijden, C.V. dan Harun. (1981). Alat-Alat Perkakas 3. Bandung : Bina Cipta.

Achmad, M, , 2004, Pengantar Ilmu Pendidikan, Semarang: UPT UNNES Press 